\title{
"Self-portrait" and other graphic tests in psychological diagnosis of children and adolescents with developmental disorders
}

Natalia Zvereva ${ }^{1}, 2$ Tatiana Goryacheva, ${ }^{2}{ }^{3}$ Mariia Zvereva ${ }^{1}$, Aleksey Koval- Zaitsev ${ }^{1}{ }^{2}$

1.Mental Health Research Center; nwzvereva@mail.ru, maremerald@gmail.com 2. Moscow State University of Psychology and Education; koval-zaitsev@mail.ru 3. Pirogov Russian National Research Medical University; tg_goriatcheva@mail.ru

\section{INTRODUCTION}

Usage of drawing techniques in psychological research and diagnosis of child development has long history. In the work ${ }^{3} s$ of $G$. Kerschenshteyner we find descriptions of various drawings of children with developmental pathologies [1]. Russian psychiatrist V.M. Bekhterev had also interest in the development of a child's drawing and its features in disturbed ontogenesis (1908) [2]. Specific methods were born in the first third of the 20th century: the Goodenough test (1928) [2], the Machover test (1949) [4].In modern studies, "draw a person" method is used in various modifications, not all authors see it as a sufficiently reliable and standardized method [3.4,5]. In Russian psychological traditions, these methods are used actively, not only in assessing the cognitive and emotional-personal sphere, but also to identify and qualify the impaired development of a child. In A.L.Venger work, projective and cognitive components of picture are analyzed for different types of dysontogenesis or cases of psychological trauma. Test may be applied in several aspects: assessment of cognitive, projective, and motor component. [6].Usage test «Drawing of Yourself» in diagnosis of children and adolescents with impaired development (mental, somatic) is very important.

PURPOSE is to assess the possibilities of applying the "Drawing of yourself" technique in a clinical and psychological study of children and adolescents with impaired development (mental or somatic illness).

\section{MATERIAL and METHODS}

\section{patients of hospital MHRC 11-16 y.o}

Samples1 (S1) 58 (mean age 12,7; 37 boys) beginning of mental disorders before $10 \mathrm{y} .0$.

Samples 2 (S2) 55 (55 (mean age 13,7; 23 boys) patients beginning of mental disorders after 10 y.o patients of somatic outpatient hospital 5-16 y.o.

Samples 3 (S3) 25 (mean age 11,4; 10 boys) with somatic disorders.

Method: test «Picture Yourself» and modifications. Evaluation parameters:

Size, location on the paper, type, quality of drawing (rating from 1 to 10), limbs, clothes and features of the drawing. SPSS v.21, U-criteria Mann-Whitney, $\Phi$ criteria.

\section{RESULTS}

DISCUSSION

Comparison boys and girls in S1, S2 and S3 We have some difficulties in wide discussing our according to assessment of age of patient, results because of a few studies with the test parameters of drawing and age of beginning of "Drawing yourself" in child clinical psychology mental disorders is presented on table 1.

Table 1. Difference between boy and girls in size, type of drawing and deviation figure from the vertical (significance Mann-Whitney u test)

\begin{tabular}{|l|c|c|c|}
\hline \multicolumn{1}{|c|}{ Group } & Size & $\begin{array}{c}\text { Type of } \\
\text { image }\end{array}$ & $\begin{array}{c}\text { Deviation } \\
\text { from the } \\
\text { vertical }\end{array}$ \\
\hline S1 & $\mathrm{p} \leq, 031$ & $\mathrm{p} \leq, 031$ & $\mathrm{p} \leq, 031$ \\
\hline $\mathrm{S} 2$ & $\mathrm{p} \leq, 000$ & $\mathrm{p} \leq, 000$ & $\mathrm{p} \leq, 031$ \\
\hline S3 & $\mathrm{p} \leq, 918$ & $\mathrm{p} \leq, 606$ & $\mathrm{p} \leq, 142$ \\
\hline
\end{tabular}

Figure 1. Distribution of types of picture in comparing groups

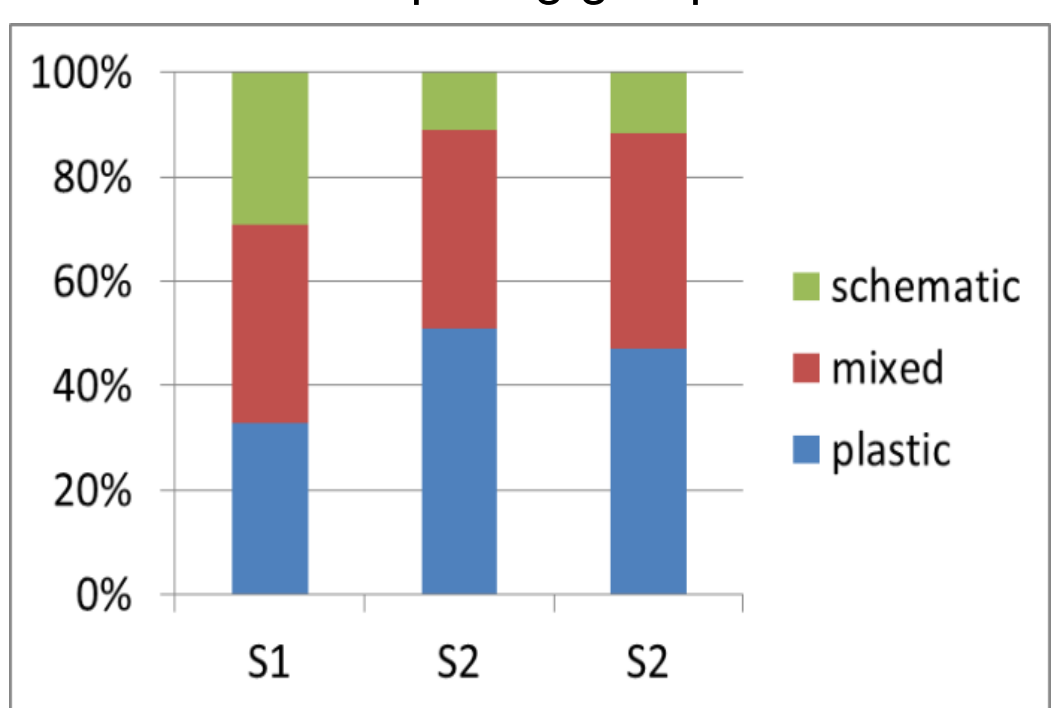

$4,5]$. Our findings in general seem like those in other works, that concerns development of drawing ability in children [1-6]. Our study allows differing drawings done by children with early and late beginning of diseases. We obtained data that allow us to differentiate patients with different diagnoses, based on the selected parameters of the figures, primarily the quality of the image and the type of image. We obtained very interesting results about specific feathers of drawing children with somatic disorder and their investigation must be continue. We can take more complicated statistical procedure; expand the sample, especially in group with somatic patients. The data obtained due to using test "Drawing of yourself" nevertheless allow us to make some conclusions of the results of the study.

Drawings of children from different samples are presented on figures 2-6.

\section{CONCLUSIONS}

1. Drawings of girls with mental disorders are better than boys (picture quality parameter),

We obtained significant difference in $\mathrm{S} 1$ and however in the group of somatic disorders there S2 in representation types of drawing are no such differences.

(images). Figure 1 demonstrates this: in S1 2. Girls more often use a plastic type of drawing, schematic type is more frequent then in S2 and boys - a schematic image method, for $(p \leq, 01, \varphi=2,449)$. Plastic type of drawing in somatic disorders there are no differences S2 more common than in $S 1(p \leq, 05, \varphi=1$, between boys and girls according to the method 951). S2 and S3 have no any distinctions.

REFERENSES (type).

Kershenshteiner G.,Lamprext K. Develop

2. Bekhterev V.M. Problems of development and education of man. - Moskva-Voronezh 2010. - p. 167-224.

3. Goodenough, F. L.: Studies in the psychology of children's drawings. Psychological Bulletin, 1928, 25:pp.272-283

4. Machover, K. (1949). Personality projection in the drawings of the human figure. Springfield, IL: C.C. Thoma

5. Cox M. V. Children's drawings of the human figure. - Psychology Press, 2013.

6. Venger A. L. Psychological drawing tests. Moscow., 2003.160 p. (in Russ.)
3. The age of onset of mental illness is related to the quality of the drawings: a higher score for those who fall ill after 10 years; and according to the type (method) of the image - who has earlier, onset of illness often uses a schematic image. 4. The obtained data require attention to the application of the technique of drawing yourself and expanding its usage in clinical and psychological researches. Sample 1. Boy 14 y.o.

\section{DRAWINGS BY PATIENTS OF PRESENTED} SAMPLES

Figure 2.

Figure 3.
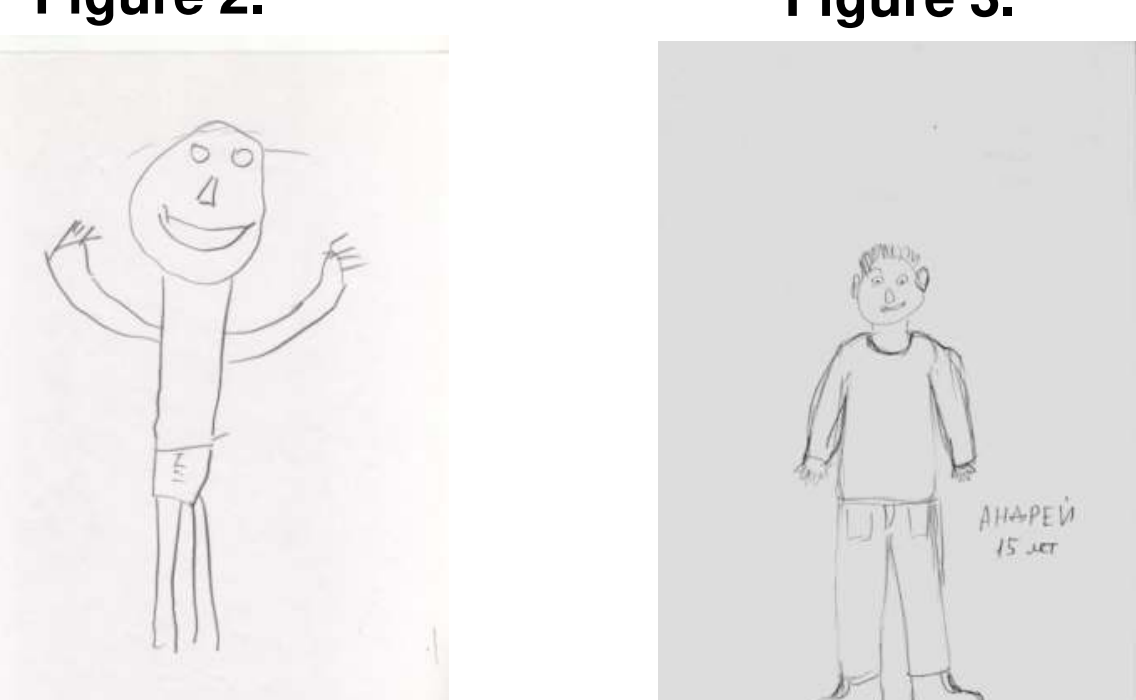

Sample 1. Boy 14 y.o.F20.8 Boy 15 y.o. F21.4

Figure 4.

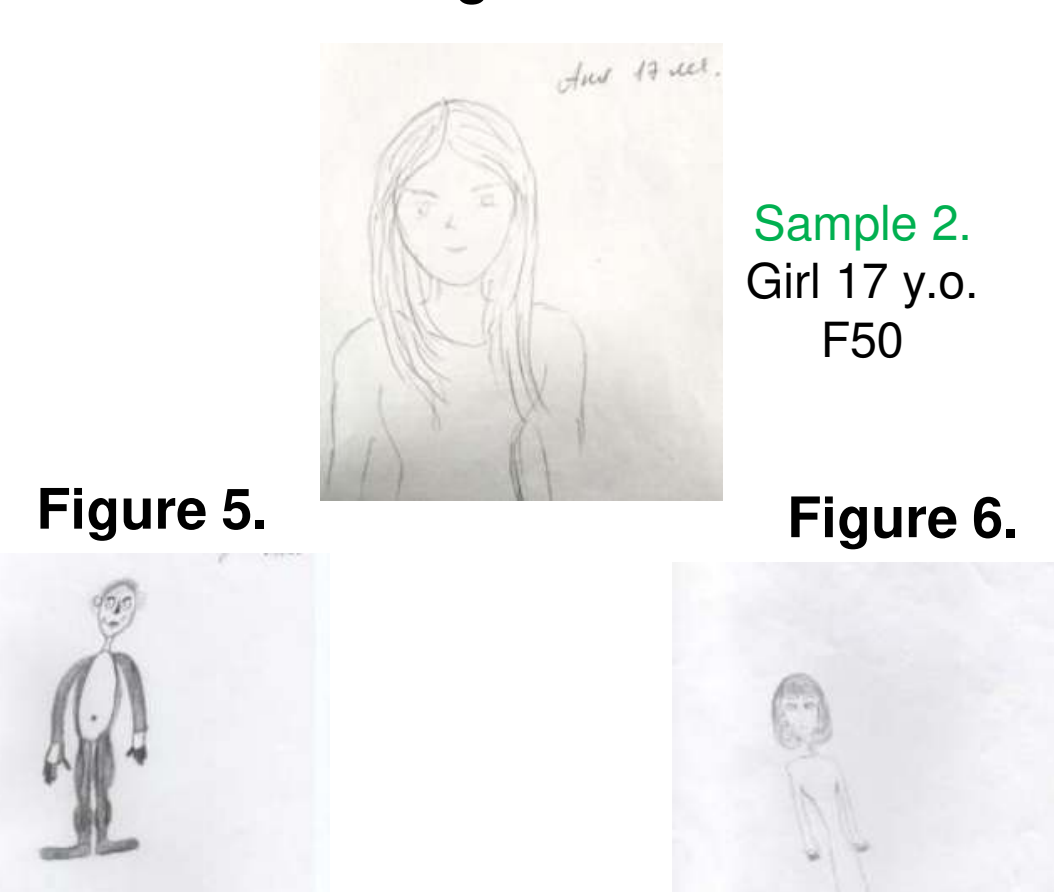

Sample 3. Boy, 13 somatic disorder Girl 15, somatic disorder Copyright (C 2019 Author N.Zvereva et al., nwzvereva@mail.ru Conflicts of Interest: The authors declare no conflict of interest. 